\title{
Levels of Use and Importance of Extension Methods and Aids in the Process of Dissemination of Agricultural Technologies in the Republic of Iraq
}

\author{
Ali L. J. Al-Mashhadani ${ }^{1}$, Zeinab H. Magd ${ }^{2}$, Abd El-Halim A. Keshta ${ }^{3}$ \\ I (Dept. Agricultural Extension and Technology Transfer, College of Agriculture / Baghdad University, IRAQ) \\ ${ }^{2}$ (Dept. Rural Sociology and Agricultural Extension, College of Agriculture / Cairo University, Egypt) \\ ${ }_{3}^{3}$ (Dept. Rural Sociology and Agricultural Extension, College of Agriculture / Cairo University, Egypt)
}

\begin{abstract}
This study aimed to determine the levels of use of extension methods and aids, as well as to identify the levels of importance of extension methods and aids, in the process of dissemination agricultural technologies from the viewpoint of agricultural extension workers (AEWs) in the republic of Iraq. The study was conducted in six governorates of Iraq, four of them are located in the central area of Iraq, which are: Baghdad, Babel, Waset, and Najaf, and two are located in the southern area which are: Qadisiyah and Muthanna. The data was collected from the entire population (203) of AEWs, who are working in the extension centers and the demonstration farms in the studied governorates. The findings of the study revealed that: About three quarters of AEWs' utilization level of extension methods and aids, were medium and high $147.3 \%$ and $26.6 \%$ respectively), compared with more than a quarter of respondents, whose utilization level, were low and null (16.7\% and 9.4\% respectively).More than half of the AEWs, expressed medium and high importance of extension methods and aids (36.9\% and $21.2 \%$ respectively), compared with less than one half, whose description of the importance was low (41.9\%).
\end{abstract}

Keywords: Levels of use and importance, Extension methods and aids, Iraq.

\section{Introduction}

The extension teaching methods and aids, are great importance in agricultural extension work, they are the channels and tools used in clarifying the ideas and new agricultural technologies, as well as transferring Innovations to a wide and diversified audience of farmers [18,7,6,5].The main objective of agricultural extension as an educational system is to create desirable behavioral changes in knowledge, skills and attitudes of farmers, nevertheless the agricultural extension workers in their field activities interact with many audience who are varied in their personal characteristics, social, cultural and economic backgrounds and levels ,not to mention their different levels of expertise, the ability to understanding and perception, Therefore, the AEWs must possess the skills of how to use or employ the appropriate extension methods and aids that can face this differences, and it is very necessary for the AEWs, to diversify they use the extension methods and aids to handle these differences. Diversifying extension methods and aids could help effective dissemination of agricultural technologies to farmers [16,13, and 11].

The main reason for using multiple and diversified extension methods and aids, is to ensure that every member of farmers' audience is affected by ideas and new agricultural technologies communicated. Individual may not responds or pay attention to a given extension method or aid, but he perhaps may get affected and responds much more by another extension method or aid [12,9,8,7]. The extension methods and aids, stimulate the farmers to receive the agricultural information and skills that are transferred to them, because it utilizes more than one sense in the educational process [17].

The studies revealed, that individuals remember $10 \%$ of the things they hear and $50 \%$ of the things that they see and $90 \%$ of the things that depend on hearing, vision, and practice together $[15,20]$, and this have been confirmed by modern education theories, which called for the need to strengthen extension educational process by utilizing different extension methods and aids in the process of dissemination of agricultural technologies to the farmers [14], It worth mentioning that, extension aids increase the effectiveness of the teaching methods such as lectures, discussions, field demonstrations, meetings and other methods used in extension education [10].

In this regard, a study on the effectiveness of educational aids in teaching of facts proved that, the teaching aids are able to transfer various types of facts, better than the traditional teaching method, which did not use educational aids. And using aids also save time, as well as supporting the memorizing of the learned facts for a longer period in the memory [17].

Field studies in Iraq on the effect of extension methods namely the symposium and field demonstration in extension work, confirmed the importance of using extension symposium in teaching knowledge to farmers, 
also the importance of using field demonstration in teaching skills. The study emphasized also the need for using these methods in process of dissemination of agricultural technologies continuously [2].

Some other studies have pointed that the disparity and weakness in the using and provision of extension methods and aids, as a channels and tools for transfer and clarify of agricultural technologies, which the agricultural extension system, aim to disseminate among farmers, may eventually lead to weakening farmers' knowledge about the attributes and benefits of new agricultural technologies, that are transferred to them, in addition to lack of understanding of new agricultural practices [4,3,1].

The above introduction motivated the current study to answer the following questions:

1.1 What are the levels of using of extension methods and aids, in the process of dissemination of agricultural technologies, from the viewpoint of AEWs in the Republic of Iraq?

1.2 What are the levels of importance of extension methods and aids, in the process of dissemination of agricultural technologies, from the viewpoint of AEWs in the Republic of Iraq?

To reach to an answer to the previous research questions, the study developed the following research objectives:

1.1 Determining the levels of using extension methods and aids, in the process of dissemination of agricultural technologies, from the viewpoint of AEWs in the Republic of Iraq.

1.2 Identifying the levels of importance of extension methods and aids, in the process of dissemination of agricultural technologies, from the viewpoint of AEWs in the Republic of Iraq.

\section{Methodology}

Iraq is divided administratively, according to the administrative units guide of the general census of the population in the Central Statistics Organization [Iraqi Ministry of Planning, 2012], into three geographical regions the northern region which includes the governorates of Dohuk, Ninewa, Suleimaniya, Kirkuk, and Erbil, the central region which includes governorates of Diyala, Anbar, Baghdad, Babil, Karbala, Wasit, Salah al-Din, and Najaf, and the southern region which includes governorates of Qadisiyah, Muthanna, DhiQar, Maysan, and Basra, According to the administrative units guide of the general census of the population in the Central Statistics Organization [Iraqi Ministry of Planning, 2012]. The study relied on a stratified random sample driven from of 50\% of the central region governorates, namely: Baghdad, Babil, Wasit, Najaf as well as $40 \%$ of the southern region governorates, namely: Qadisiyah and Muthanna. The afford mentioned governorates were selected due to the good stability in terms of security, which allow the AEWs a favorable condition to perform all the tasks and activities of agricultural extension in those work areas. The study population included all agricultural extension workers performing agricultural extension tasks and activities, which amounted to 203 AEWs, employed in the extension centers and the demonstration farms in the governorates of the study. Data were collected in 2015, through personal interviews with the AEWs, by using a questionnaire which was designed and pretested for achieving the research objectives. The studied of extension methods and aids include the mass media, group and individual methods, as well as audio, visual and audio-visual aids, which use to transfer and clarify the extension messages to farmers. The levels of using were measured by asking the AEWs about the frequency of use of extension methods and aids. Their answer was classified into the following responses: always, often, sometimes, rarely, do not use. and the following scores were assigned to these responses as follows: 4,3,2,1,0 respectively. The levels of importance were measured by asking the AEWs about the importance of using extension methods and aids in the process of dissemination of agricultural technologies, their answer were classified into the following responses: very important, important to some extent, is not important. and the following scores were assigned to these responses as follows: 2,1,0 respectively. The categories, frequencies, percentage, weighted average and rank, were used for data presentation and analysis, the statistical procedure implemented by using the program SPSS [4].

\section{Results and Discussion}

\subsection{The levels of using extension methods and aids, in the process of dissemination of agricultural} technologies.

As shown in table 1, that the levels of use of extension methods and aids, rang between 0score as a minimum to 120 scores as a maximum, the levels of use were classified into four categories: null use 0score, low use 1-40scores, medium use 41-80scores, and high use 81-120scores.

Table 1. Distribution of respondents, according to the use level categories of extension methods and aids

\begin{tabular}{|l|c|c|}
\hline \multicolumn{1}{|c|}{ Categories } & NO. & $\%$ \\
\hline null use 0 score & 19 & $9.4 \%$ \\
\hline low use 1- 40 scores & 34 & $16.7 \%$ \\
\hline medium use 41-80 scores & 96 & $47.3 \%$ \\
\hline high use 81-120 scores & 54 & $26.6 \%$ \\
\hline Total & 203 & $100 \%$ \\
\hline
\end{tabular}


About three-quarters of AEWs' levels of use could be described as medium and high with $47.3 \%$ and $26.6 \%$, respectively, compared with more than a quarter of the respondents were of low level and null use with percentages $16.7 \%$ and $9.4 \%$, respectively. This indicates to a good use of extension methods and aids in the process of dissemination of agricultural technologies, by most of AEWs, so that maybe return to use a variety of extension methods and aids in their work, and this enable them to face and handle the large variation of target groups of farmers, Accordingly the AEWs could achieve improve their performance of agricultural extension tasks and activities. As shown in table 2 the most extension methods and aids used by the AEWs (in first position) were as follows: field visits to farmers, field days, extension pictures, extension posters, training courses, and extension bulletins, with weighted average value of $2.68,2.61,2.57,2.51,2.50,2.50$ respectively. As shown in table 2 the less extension methods and aids used by the AEWs (in last position) were as follows: sound recorder device, overhead device, personal messages or letters, charts, radio, and maps, with weighted average value of $1.30,1.30,1.28,1.14,1.11,1.08$ respectively.

Table 2. Distribution of the respondents according to the extent of use extension methods and aids

\begin{tabular}{|c|c|c|c|c|c|c|c|c|c|c|c|c|c|}
\hline \multirow{3}{*}{$\begin{array}{c}\text { Extension } \\
\text { methods and } \\
\text { aids }\end{array}$} & \multicolumn{10}{|c|}{ The levels of use } & \multirow{3}{*}{ No. } & \multirow{3}{*}{$\begin{array}{l}\text { weighted } \\
\text { average }\end{array}$} & \multirow{3}{*}{ Rank } \\
\hline & \multicolumn{2}{|c|}{ do not use } & \multicolumn{2}{|c|}{ rarely } & \multicolumn{2}{|c|}{ sometimes } & \multicolumn{2}{|c|}{ often } & \multicolumn{2}{|c|}{ always } & & & \\
\hline & No. & $\%$ & No. & $\%$ & No. & $\%$ & No. & $\%$ & No. & $\%$ & & & \\
\hline $\begin{array}{l}\text { Field visits to } \\
\text { farmers }\end{array}$ & 37 & 18.2 & 8 & 3.9 & 25 & 12.3 & 44 & 21.7 & 89 & 43.8 & 203 & 2.68 & 1 \\
\hline Field days & 37 & 18.2 & 8 & 3.9 & 35 & 17.2 & 40 & 19.7 & 83 & 40.9 & 203 & 2.61 & 2 \\
\hline $\begin{array}{l}\text { Extension } \\
\text { pictures }\end{array}$ & 47 & 23.2 & 5 & 2.5 & 22 & 10.8 & 43 & 21.2 & 86 & 42.4 & 203 & 2.57 & 3 \\
\hline $\begin{array}{l}\text { Extension } \\
\text { posters }\end{array}$ & 39 & 19.2 & 7 & 3.4 & 35 & 17.2 & 55 & 27.1 & 67 & 33 & 203 & 2.51 & 4 \\
\hline Training courses & 42 & 20.7 & TI & 5.4 & 33 & 16.3 & 36 & 17.7 & 81 & 39.9 & 203 & 2.50 & 5.5 \\
\hline $\begin{array}{l}\text { Extension } \\
\text { bulletins }\end{array}$ & 40 & 19.7 & 9 & 4.4 & 34 & 16.7 & 49 & 24.1 & 71 & 35.0 & 203 & 2.50 & 5.5 \\
\hline $\begin{array}{l}\text { Home visits to } \\
\text { farmers }\end{array}$ & 42 & 20.7 & 12 & 5.9 & 28 & 13.8 & 54 & 26.6 & 67 & 33 & 203 & 2.45 & 7 \\
\hline Lectures & 48 & 23.6 & 11 & 5.4 & 25 & 12.3 & 46 & 22.7 & 73 & 36.0 & 203 & 2.41 & 8 \\
\hline $\begin{array}{l}\text { Symposiums and } \\
\text { conferences }\end{array}$ & 43 & 212 & 13 & 6.4 & 36 & 17.7 & 40 & 19.7 & 71 & 35 & 203 & 2.40 & 9 \\
\hline Meetings & 43 & 21.2 & 13 & 6.4 & 36 & 17.7 & 44 & 21.7 & 67 & 33 & 203 & 2.38 & 10 \\
\hline $\begin{array}{l}\text { Field method } \\
\text { demonstrations }\end{array}$ & 48 & 23.6 & 11 & 5.4 & 26 & 12.8 & 55 & 27.1 & 63 & 31 & 203 & 2.36 & 11 \\
\hline $\begin{array}{l}\text { Field result } \\
\text { demonstrations }\end{array}$ & 50 & 24.6 & 14 & 6.9 & 26 & 12.8 & 45 & 22.2 & 68 & 33.5 & 203 & 2.33 & 12 \\
\hline $\begin{array}{l}\text { Data show } \\
\text { device }\end{array}$ & 53 & 26.1 & 11 & 5.4 & 36 & 17.7 & 43 & 21.2 & 60 & 29.6 & 203 & 2.22 & 13 \\
\hline Internet & 60 & 29.6 & 24 & 11.8 & 31 & 15.3 & 21 & 10.3 & 67 & 33.0 & 203 & 2.05 & 14 \\
\hline $\begin{array}{l}\text { Agricultural } \\
\text { exhibitions or } \\
\text { galleries }\end{array}$ & 43 & 21.2 & 31 & 15.3 & 51 & 25.1 & 34 & 16.7 & 44 & 21.7 & 203 & 2.02 & 15 \\
\hline $\begin{array}{l}\text { Computer } \\
\text { device }\end{array}$ & 60 & 29.6 & 22 & 10.8 & 37 & 18.2 & 33 & 16.3 & 51 & 25.1 & 203 & 1.96 & 16 \\
\hline Real stuff & 59 & 29.1 & 26 & 12.8 & 34 & 16.7 & 34 & 16.7 & 50 & 24.6 & 203 & 1.95 & 17 \\
\hline Blackboard & 60 & 29.6 & 22 & 10.8 & 35 & 17.2 & 44 & 21.7 & 42 & 20.7 & 203 & 1.93 & 18 \\
\hline $\begin{array}{l}\text { Extension } \\
\text { movies }\end{array}$ & 64 & 31.5 & 20 & 9.9 & 47 & 23.2 & 30 & 14.8 & 42 & 20.7 & 203 & 1.83 & 19 \\
\hline Samples & 66 & 32.5 & 22 & 10.8 & 39 & 19.2 & 36 & 17.7 & 40 & 19.7 & 203 & 1.81 & 20 \\
\hline $\begin{array}{l}\text { Telephone and } \\
\text { mobile phones }\end{array}$ & 80 & 39.4 & 22 & 10.8 & 27 & 13.3 & 33 & 16.3 & 41 & 20.2 & 203 & 1.66 & 21 \\
\hline Audio speakers & 88 & 43.3 & 26 & 12.8 & 35 & 17.2 & 28 & 13.8 & 26 & 12.8 & 203 & 1.39 & 22 \\
\hline $\begin{array}{l}\text { Synthetic or } \\
\text { artificial models }\end{array}$ & 87 & 42.9 & 34 & 16.7 & 26 & 12.8 & 31 & 15.3 & 25 & 12.3 & 203 & 1.37 & 23.5 \\
\hline $\begin{array}{l}\text { Display boards } \\
\text { (wood or glass) }\end{array}$ & 85 & 41.9 & 31 & 15.3 & 34 & 16.7 & 31 & 15.3 & 22 & 10.8 & 203 & 1.37 & 23.5 \\
\hline $\begin{array}{l}\text { Sound Recorder } \\
\text { device }\end{array}$ & 95 & 46.8 & 27 & 13.3 & 30 & 14.8 & 26 & 12.8 & 25 & 12.3 & 203 & 1.30 & 25.5 \\
\hline Overhead device & 87 & 42.9 & 32 & 15.8 & 38 & 18.7 & 28 & 13.8 & 18 & 8.9 & 203 & 1.30 & 25.5 \\
\hline $\begin{array}{l}\text { Personal } \\
\text { messages or } \\
\text { letters }\end{array}$ & 89 & 43.8 & 29 & 14.3 & 42 & 20.7 & 24 & 11.8 & 19 & 9.4 & 203 & 1.28 & 27 \\
\hline Charts & 92 & 45,3 & 36 & 17.7 & 39 & 19.2 & 25 & 12.3 & 11 & 5.4 & 203 & 1.14 & 28 \\
\hline Radie & 99 & 48.8 & 34 & 16.7 & 32 & 15.8 & 24 & 11.8 & 14 & 6.9 & 203 & 1.11 & 29 \\
\hline Maps & 90 & 44.3 & 45 & 22.2 & 39 & 19.2 & 19 & 9.4 & 10 & 4.9 & 203 & 1.08 & 30 \\
\hline
\end{tabular}




\subsection{The levels of importance of extension methods and aids, in the process of dissemination of agricultural technologies.}

As shown in table 3, that the levels of importance of extension methods and aids, rang between 17 scores as a minimum to 60 scores as a maximum, the levels of importance were classified into three categories: low importance 17-31scores, medium importance 32-46scores, and high importance 47-60scores.

Table 3. Distribution of respondents according to the importance level categories of extension methods and aids

\begin{tabular}{|l|c|c|}
\hline Categories & NO. & $\%$ \\
\hline low importance 17 - 31 scores & 85 & $41.9 \%$ \\
\hline medium importance 32 - 46 scores & 75 & $36.9 \%$ \\
\hline high importance 47 - 60 scores & 43 & $21.2 \%$ \\
\hline Total & 203 & $100 \%$ \\
\hline
\end{tabular}

The findings show that, more than half of the AEWs, expressed medium and high levels importance $36.9 \%$ and $21.2 \%$ respectively, compared to less than one half, of those who expressed a low level of importance $41.9 \%$.

This indicates to high levels of awareness and perception of the importance of using extension methods and aids, in the process of dissemination of agricultural technologies, by more than half of AEWs. This means that the increase in the importance perception of using extension methods and aids in agricultural extension work, could lead to increase the levels of use of extension methods and aids, which in turn help to clarify specific agricultural technology, consequently it would guarantee affecting most farmers, with the information about the ideas and the new agricultural technologies, which are provided by the agricultural extension organization.

However, considerable proportion of the AEWs 41.9\%described the levels of importance as low in their work; this may be due to the low levels of their knowledge and experience about the importance and usefulness of extension methods and aids, in the process of dissemination of agricultural technologies.

Some AEWs, on the other hand might believe that some of extension methods and aids are out dated or become too old, such as sound recorder device, and personal messages or letters.

Or this may be attributed to the believe of some AEWs, that there is a high material and financial cost associated with the preparation and implementation of some extension methods and aids, such as agricultural exhibitions or galleries, extension movies, Synthetic or artificial models, compared to the expected benefits of using them in the process of dissemination of agricultural technologies.

Based on the weighted average, the extension methods and aids could be ranked according to the high important, as follows: field visits to farmers, extension pictures, field days, data show device, audio speakers, training courses, with weighted average value of $1.46,1.42,1.41,1.40,1.38,1.37$ respectively.

While, based on the weighted average, the extension methods and aids could be ranked according to the less important, as follows: radio, computer device, overhead device, personal messages or letters, maps, charts, sound recorder device, with weighted average value of 1.02, 1.02, 1.02, 1.01, 1.009, 0.97, 0.96 respectively.

Table 4. Distribution of the respondents according to the extent of importance of using extension methods and aids

\begin{tabular}{|c|c|c|c|c|c|c|c|c|c|}
\hline \multirow{3}{*}{ Extension methods and aids } & \multicolumn{6}{|c|}{ Levels of importance } & \multirow{3}{*}{ No. } & \multirow{3}{*}{ 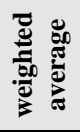 } & \multirow{3}{*}{ Rank } \\
\hline & \multicolumn{2}{|c|}{$\begin{array}{c}\text { is not } \\
\text { important }\end{array}$} & \multicolumn{2}{|c|}{$\begin{array}{c}\text { important to } \\
\text { some extent }\end{array}$} & \multicolumn{2}{|c|}{$\begin{array}{c}\text { very } \\
\text { Important }\end{array}$} & & & \\
\hline & No. & $\%$ & No. & $\%$ & No. & $\%$ & & & \\
\hline Field visits to farmers & $\mathbf{0}$ & $\mathbf{0}$ & 108 & 53.2 & 95 & 46.8 & 203 & 1.46 & 1 \\
\hline Extension pictures & 5 & 2.5 & 106 & 52.2 & 92 & 45.3 & 203 & 1.42 & 2 \\
\hline Field days & 3 & 1.5 & 113 & 55.7 & 87 & 42.9 & 203 & 1.41 & $\mathbf{3}$ \\
\hline Data show device & 1 & 0.5 & 119 & 58.6 & 83 & 40.9 & 203 & 1.40 & 4 \\
\hline Audio speakers & 4 & 2 & 117 & 57.6 & 82 & 40.4 & 203 & 1.38 & 5 \\
\hline Training courses & 4 & 2 & 119 & 58.6 & 80 & 39.4 & 203 & 1.37 & 6 \\
\hline Home visits to farmers & 6 & 3 & 116 & 57.1 & 81 & 39.9 & 203 & 1.36 & 7.5 \\
\hline Lectures & 4 & 2 & 120 & 59.1 & 79 & 38.9 & 203 & 1.36 & 7.5 \\
\hline Extension bulletins & 6 & 3 & 121 & 59.6 & 76 & 37.4 & 203 & 1.34 & 9.5 \\
\hline Symposiums and conferences & 5 & 2.5 & 123 & 60.6 & 75 & 36.9 & 203 & 1.34 & 9.5 \\
\hline Meetings & 4 & 2 & 128 & 63 & 71 & 35 & 203 & $\mathbf{1 . 3 3}$ & 11 \\
\hline Field result demonstration & 3 & $\mathbf{1 . 5}$ & 131 & 64.5 & 69 & 34 & 203 & 1.32 & 12 \\
\hline Field method demonstration & 7 & 3.4 & 125 & 61.6 & 71 & 35 & 203 & 1.31 & 13.5 \\
\hline Extension posters & 3 & $\mathbf{1 . 5}$ & 133 & 65.5 & 67 & 33 & 203 & 1.31 & 13.5 \\
\hline Internet & 13 & 6.4 & 123 & 60.6 & 67 & 33 & 203 & 1.26 & 15 \\
\hline Agricultural exhibitions or galleries & 6 & 3 & 140 & 69 & 57 & 28.1 & 203 & 1.25 & $\mathbf{1 7 . 5}$ \\
\hline Real stuff & 14 & 6.9 & 123 & 60.6 & 66 & 32.5 & 203 & 1.25 & $\mathbf{1 7 . 5}$ \\
\hline
\end{tabular}


Levels of Use and Importance of Extension Methods and Aids in The Process of Dissemination of

\begin{tabular}{|c|c|c|c|c|c|c|c|c|c|}
\hline \multirow{3}{*}{ Extension methods and aids } & \multicolumn{6}{|c|}{ Levels of importance } & \multirow{3}{*}{ No. } & \multirow{3}{*}{ 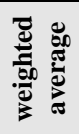 } & \multirow{3}{*}{ Rank } \\
\hline & \multicolumn{2}{|c|}{$\begin{array}{c}\text { is not } \\
\text { important }\end{array}$} & \multicolumn{2}{|c|}{$\begin{array}{c}\text { important to } \\
\text { some extent }\end{array}$} & \multicolumn{2}{|c|}{$\begin{array}{c}\text { very } \\
\text { Important }\end{array}$} & & & \\
\hline & No. & $\%$ & No. & $\%$ & No. & $\%$ & & & \\
\hline Samples & 15 & 7.4 & 122 & 60.1 & 66 & 32.5 & 203 & 1.25 & $\mathbf{1 7 . 5}$ \\
\hline Extension movies & 7 & 3.4 & 137 & 67.5 & 59 & 29.1 & 203 & 1.25 & $\mathbf{1 7 . 5}$ \\
\hline Blackboard & 15 & 7.4 & 124 & 61.1 & 64 & 31.5 & 203 & 1.24 & 20 \\
\hline Telephone and mobile phones & 16 & 7.9 & 128 & 63.1 & 59 & 29.1 & 203 & 1.21 & 21 \\
\hline Synthetic or artificial models & 25 & 12.3 & 133 & 65.5 & 45 & 22.2 & 203 & 1.09 & 22 \\
\hline Display boards (a wood or a glass) & 21 & $\mathbf{1 0 . 3}$ & 145 & 71.4 & 37 & 18.2 & 203 & 1.07 & 23 \\
\hline Radio & 30 & $\mathbf{1 4 . 8}$ & 137 & 67.5 & 36 & 17.7 & 203 & $\mathbf{1 . 0 2}$ & 25 \\
\hline Computer device & 28 & $\mathbf{1 3 . 8}$ & 141 & 69.5 & 34 & 16.7 & 203 & 1.02 & 25 \\
\hline Overhead device & 22 & $\mathbf{1 0 . 8}$ & 153 & 75.4 & 28 & 13.8 & 203 & 1.02 & 25 \\
\hline Personal messages or letters & 29 & 14.3 & 142 & 70 & 32 & 15.8 & 203 & 1.01 & 27 \\
\hline Maps & 25 & 12.3 & 151 & 74.4 & 27 & $\mathbf{1 3 . 3}$ & 203 & 1.009 & 28 \\
\hline Charts & 31 & 15.3 & 146 & 71.9 & 26 & 12.8 & 203 & 0.97 & 29 \\
\hline Sound Recorder device & 34 & 16.7 & 142 & 70 & 27 & 13.3 & 203 & 0.96 & 30 \\
\hline
\end{tabular}

\section{Conclusion}

4.1 About three-quarters of AEWs' levels of use could be described as medium and high, this indicates to a good use of extension methods and aids in the process of dissemination of agricultural technologies, by most of AEWs, so that maybe return to use a variety of extension methods and aids in their work.

4.2 The most extension methods and aids used by the AEWs in first position were as follows: field visits to farmers, field days, extension pictures, extension posters, training courses, and extension bulletins, and the less extension methods and aids used by the AEWs in last position were as follows: sound recorder device, over Head device, personal messages or letters, charts, radio, and maps.

4.3 More than half of the AEWs, expressed medium and high levels importance, compared to less than one half, of those who expressed a low level of importance of extension methods and aids in the process of dissemination of agricultural technologies.

4.4 The extension methods and aids could be ranked according to the high important, as follows: field visits to farmers, extension pictures, field days, data show device, audio speakers, training courses, and the extension methods and aids could be ranked according to the less important, as follows: radio, computer device, overhead device, personal messages or letters, maps, charts, sound recorder device.

\section{Recommendations}

Based on the result and conclusion of study, the following recommendations could be suggested:

5.1 The AEWs' levels of use of extension methods and aids, in the process of dissemination of agricultural technologies, require regular and continuous improvement; this could be achieved through increasing the number of quality training courses for AEWs, which would improve and enhance the AEWs' perception and awareness level of the importance of extension methods and aids.

5.2 Increasing the budgets allocated to field extension work in addition to increasing the effective and timely utilization of extension methods and aids that enhance the AEWs performance in the process of dissemination of agricultural technologies.

\section{Acknowledgement}

I wish to express my sincere thanks, deepest gratitude and appreciation to Dr. Mohamed H. Abdel Aaal, Dr. Emad M. El-shafie, Dr. Zeinab H. Magd, Dr. Abd El-halim A. Keshta, Professors of Agricultural Extension, Dept. Rural Sociology and Agricultural Extension, Faculty of Agriculture, Cairo University, for help and guidance through the course of study. And I wish to express my sincere thanks, deepest gratitude and appreciation to all the people who helped me in collecting data for the study.

\section{References}

[1] AL-ANI. Bilal. R. Ch, Farmers Exposure to Some Methods and Means Extension and Activating Benefit from in the Field, Master Thesis., College of Agriculture, Baghdad University,2006, 1.

[2] AL-MAMORY. Sabah. H. M, The Effect of Each Methods of the Extension Symposium and Field Demonstration and The Sequence of Them in Developing Knowledge and Skill for Sheep Breeders in Field of Mating (An Experimental Study in AL-WASAMA Village of Babylon Governorate), Doctor Thesis., College of Agriculture, Baghdad University, 2002, 1-2.

[3] AL-MASHHADANI. Ali L. J, Using "Extension means" In Process of Dissemination of Agricultural Technologies from Viewpoint of Agricultural Extension Workers and Relationship with Some Related Factors, The Iraqi Journal of Agricultural Sciences. 42(5), 2011,80-97.

[4] AL-MASHHADANI. Ali L. J, Evaluation of Planning and Implementation Process OF Field Days in Some of IRAQI Middle Governorates, Master Thesis., College of Agriculture, Baghdad University,2009, 1. 
[5] AL-SAMURAI. Abdullah. A, and AL-GADIRA. Adnan. H, Agricultural Extension Science,(Baghdad, College of Agriculture, 1990) 284-285.

[6] Burton. Swanson, Improving Agricultural Extension,(Rome, Food and Agriculture Organization of the United Nations, 1998) 2-5

[7] F. Van day, Social Principles for Agricultural Extension to Assist in the Promotion of Natural Resource management, Australian Journal of Experimental Agriculture. 44(3), 2004, 213-222.

[8] Fred. White ford, Social Psychology,(New York, Williams College, 2002) 102-114.

[9] General Organization for Technical Education and Vocational Training, Agricultural Extension,(Saudi Arabia, The General Organization for Technical Education and Vocational Training, 2004) 78-85.

[10] Huwaidi. Zaid, Science Teaching Methods of Basic Phase,(United Arab Emirates, University Book House, 2005) 115-142.

[11] John. Farrington, Agricultural Extension. Overseas Development Institute,(London, 2010) 1-7.

[12] Mark. Galpin, Peter. Dorward, and Derek. Shepherd, Participatory Farm Management methods for Agricultural Research and Extension,(United Kingdom, The University of Reading, 2000) 1-10.

[13] Rohonda. L. Miller, and Loralie. Cox, Technology Transfer Preferences of Researchers and Producers in Sustainable Agriculture, Journal of Extension. 44(3),2006, www.joe.org/joe/2006june/rb2.php.

[14] Mustafa. Sabr, Agricultural Extension and Its Methods and Means of Education,(Libyan Arab Republic, Omar Mukhtar University, 1997) 277.

[15] Paul. Burns, Teaching Reading,(New York, University of Tennessee at Knoxville, 2002)358

[16] Robert. Chapman, And Robert. Tripp, Changing incentives for agricultural extension are view of privatized extension in practice,(United Kingdom, Agricultural research \& extension, 2003) 1-4.

[17] Salama. Abd Alhafez, 2000. Educational and curriculum means,(Amman, Jordan, 2000) 73-108.

[18] Anna. S. Toness,2001. The potential of participatory rural appraisal (PRA) approaches and methods for agricultural extension and development in the 21st century. Journal of international agricultural and extension education, 8(1), 2001,25-37.

[19] Zaghloul. Saad, Your guide to the statistical program (SPSS),(Iraq, Baghdad, Arab institute for training and statistical research, 2003)132.

[20] Zaki. Hussein, (No date). Agricultural Extension and Its Role in Rural Development,(Egypt, Cairo) 111. 